\title{
ENAMEL SUSCEPTIBILITY TO RED WINE STAINING AFTER 35\% HYDROGEN PEROXIDE BLEACHING
}

\author{
Sandrine Bittencourt BERGER ${ }^{1}$, Alessandra Sanchez COELHO ${ }^{2}$, Valéria Aparecida Pessatti OLIVEIRA ${ }^{3}$, \\ Vanessa CAVALLI ${ }^{4}$, Marcelo GIANNINI ${ }^{5}$
}

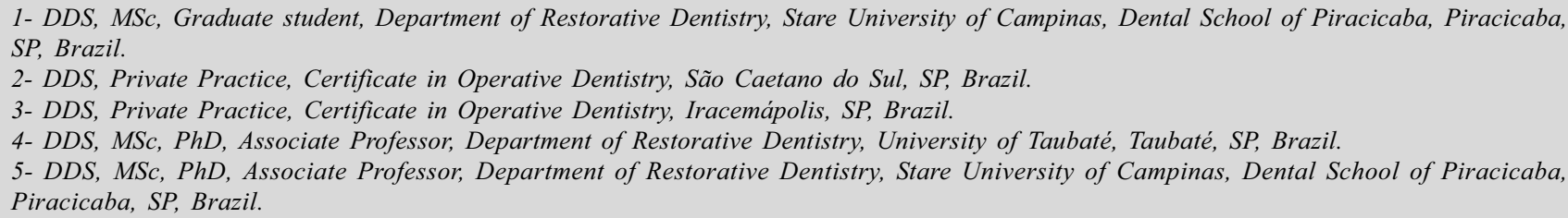

Corresponding address: Prof. Dr. Marcelo Giannini - Piracicaba Dental School - State University of Campinas - Department of Restorative Dentistry - Operative Dentistry - Av. Limeira, 901 - Areião - CP 52 - 13414-903 - Piracicaba - SP - Brazil - Phone: 551921065340 - Fax: 55 1921065218 - e-mail: giannini@fop.unicamp.br

Received: December 14, 2007 - Modification: March 1, 2008 - Accepted: March 8, 2008

\begin{abstract}
C

oncern has been expressed regarding the staining of enamel surface by different beverages after bleaching. This study investigated the influence of $35 \%$ hydrogen peroxide bleaching agents on enamel surface stained with wine after whitening treatments. Flat and polished bovine enamel surfaces were submitted to two commercially available $35 \%$ hydrogen peroxide bleaching agents or kept in $100 \%$ humidity, as a control group $(n=10)$. Specimens of all groups were immersed in red wine for $48 \mathrm{~h}$ at $37^{\circ} \mathrm{C}$, immediately, $24 \mathrm{~h}$ or 1 week after treatments. All specimens were ground into powder and prepared for the spectrophotometric analysis. Data were subjected to two-way analysis of variance and Fisher's PLSD test at 5\% significance level. The amount of wine pigments uptake by enamel submitted to bleaching treatments was statistically higher than that of control group, independently of the evaluation time. Results suggested that wine staining susceptibility was increased by bleaching treatments.
\end{abstract}

Key words: Hydrogen peroxide. Tooth bleaching. Dental enamel.

\section{INTRODUCTION}

Dentists have advised patients against drinking some beverages and smoking particularly after bleaching session with $35 \%$ hydrogen peroxide, since some studies have reported superficial enamel alterations promoted by bleaching products. Hydrogen peroxide can promote varying/assorted degrees of surface porosity, structural and permeability changes, depending on the bleaching agent ${ }^{6,12,13,21}$. Changes on enamel surface would be attribute to oxidative and demineralization processes produced by the hydrogen peroxide agents ${ }^{8,11,20}$.

Coffee, tea, juices, wines and cola-based soft drinks are potential dark or coloring beverages, which could stain or discolor the bleached enamel surface. Some of them are acidic solutions that can increase the demineralization, while others contain ethanol and/or pigments. In addition, certain beverages, artificial food colorations and smoking used with a high frequency are considered responsible for primary staining, dark and discoloration of teeth ${ }^{2,4}$. It is possible that bleached enamel surface would be more susceptible to staining, in particular to red wine, which is an acidic, colored and an alcoholic beverage.

Since limited information about post-bleaching enamel staining is available and these effects have not been thoroughly investigated, the purpose of this study was to evaluate the influence of two $35 \%$ hydrogen peroxide bleaching agents on the enamel surface susceptibility to wine staining. The tested null hypothesis was that enamel staining susceptibility to wine is not influenced by whitening treatments regardless of the type of bleaching agent used.

\section{MATERIALAND METHODS}

Eighteen extracted sound bovine incisors stored in $0.1 \%$ thymol solution were used within 1 month of extraction. The roots were separated from the crowns with a watercooled low-speed diamond saw (Isomet, Buehler Ltd., Lake 
Bluff, IL, USA). Crowns were sectioned mesiodistally and buccolingually to obtain 4 dental blocks ( $4 \mathrm{~mm}$ long X $3 \mathrm{~mm}$ wide X $3 \mathrm{~mm}$ thick) from each crown. Buccal enamel surfaces were flattened with wet 600-, 1000- and 1200-grit aluminum oxide abrasive papers and polished with $6,3,1 / 2$, and $1 / 4 \mathrm{~mm}-$ grit diamond pastes on a polishing machine (APL 4, Arotec, Cotia, SP, Brazil).

Except for flattened surfaces, other surfaces of the dental blocks were coated with two layers of nail varnish (Revlon Inc., New York, NY, USA). Seventy dental blocks were randomly assigned to 7 groups $(\mathrm{n}=10)$, as follow: Group 1 (unbleached control group) - specimens kept in $100 \%$ humidity at $37^{\circ} \mathrm{C}$; Groups $2 \mathrm{a}, 2 \mathrm{~b}$ e $2 \mathrm{c}$ : specimens bleached with Pola Office (SDI, Bayswater, Victoria, Australia); Groups 3a, 3b e 3c: specimens bleached with Whiteness HP Maxx (FGM Prod. Odont., Joinville, SC, Brazil).

Table 1 shows the composition of the bleaching agents, which were prepared according to manufacturers' instructions. Two milliliter of each bleaching paste $(35 \%$ hydrogen peroxide) was dispensed on enamel surface for $20 \mathrm{~min}$, left undisturbed for $1 \mathrm{~min}$ and submitted to three 2.5 min light irradiation cycles with a light-emitting diode (LED) source (Ultrablue Laser System, DMC, São Carlos, SP, Brazil). The application protocol was repeated 3 times. Bleaching agent was removed by suction and the specimens were rinsed with distilled water at the end of bleaching process.

Specimens from Groups $2 \mathrm{a}$ and $3 \mathrm{a}$ were immersed in red wine (Bolla Valpolicella, Fratelli Bolla S.P.A., Verona, Italy) for $48 \mathrm{~h}$ at $37^{\circ} \mathrm{C}$. Each group was immersed in $200 \mathrm{~mL}$ de red wine. Specimens from Groups $2 b, 2 c, 3 b$ and $3 c$ were stored in a mineralizing solution ${ }^{17}$ for $24 \mathrm{~h}$ (groups $2 \mathrm{~b}$ and $3 \mathrm{~b}$ ) or 7 days (groups 2c and 3c) and after these periods the specimens were immersed in wine for $48 \mathrm{~h}$ at $37^{\circ} \mathrm{C}$. Afterwards, specimens were removed from the wine, rinsed in distilled water for 15 seconds and placed in an oven (MA033, Marconi, Piracicaba, SP, Brazil) for 30 minutes at $37^{\circ} \mathrm{C}$.

The nail varnish was removed from the surfaces of the blocks with a Le Cron carver (Duflex - SS White, Juiz de Fora, MG, Brazil) and the specimens were ground into powder in a mill for hard tissues (MA-345, Marconi, Piracicaba, SP, Brazil). The resulting powder was placed separately into test tubes, which were filled with $1 \mathrm{~mL}$ of absolute alcohol (Synth, Diadema, SP, Brazil). After 24 h, the solutions were centrifuged (IC-15AN, Tomy Seiko Co. LTD., Tokyo, Japan) at 3,000 rpm for $3 \mathrm{~min}$ and the supernatant used to determine the absorbance in a spectrophotometer (DU 65, Beckman Inc, Fullerton, CA, USA). The spectrophotometer was previously calibrated with standard solutions of red wine $(0$

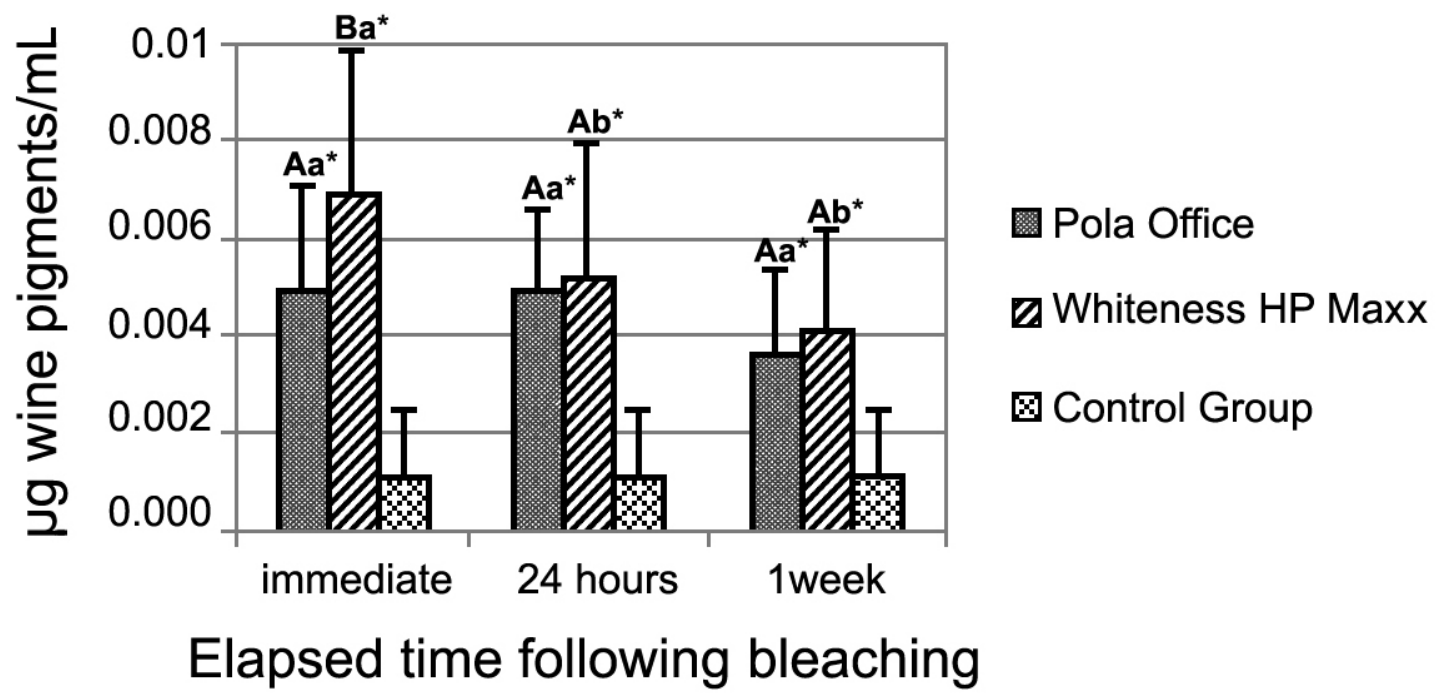

FIGURE 1- Bar graph of mean values $( \pm \mathrm{SD})$ of wine pigment uptake $(\mathrm{mg}$ wine pigments $/ \mathrm{mL})$ from bleached and unbleached (control) enamel surfaces.

* Differ from the control group. Mean values followed by different lowercase letters (comparison among elapsed times following bleaching for the same bleaching agent) or uppercase letters (comparison between bleaching agents at the same elapsed time following bleaching) differ significantly by Fisher test $(p<0.05)$

TABLE 1- Bleaching agent compositions 
to $0.2 \mu \mathrm{g}$ ) diluted in $1 \mathrm{~mL}$ of absolute alcohol.

The absorbance of the standard solutions was determined at $660 \mathrm{~nm}$ wavelengths. Prior to determining the absorbance of the experimental solutions, the correlation coefficient ( $r$ ) between dye concentration and absorbance of the standard solutions was calculated, and presented an "r" value of 0.984 . To estimate the dye concentration on the experimental specimens, a linear regression was obtained. The regression equation was expressed as: $\mathrm{y}=0.046 \mathrm{x}-$ 0.0007 , where " $y$ " is the absorbance and " $x$ " is the concentration of wine pigments. The wine pigments uptake of each specimen was expressed in $\mathrm{mg}$ wine pigments $/ \mathrm{mL}$, lower values indicating lower staining susceptibility. Data from the spectrophotometric analysis were analyzed statistically by two-way analysis of variance (ANOVA) and Fisher's PLSD test at 5\% level of significance.

\section{RESULTS}

The mean wine pigments uptakes by dental enamel of the experimental groups are displayed in Figure 1. Unbleached surfaces (control group) were more resistant to staining than $35 \%$ hydrogen peroxide-bleached enamel surfaces $(\mathrm{p}<0.05)$ for all time intervals evaluated after whitening. Immediately after bleaching, Whiteness HP Maxx yielded more $\mathrm{mg}$ wine pigments $/ \mathrm{mL}$ than Pola Office. For the other times elapsed after bleaching ( $24 \mathrm{~h}$ and 1 week), no significant differences were found between bleaching agents $(p>0.05)$. Pola Office exhibited the same mean values of wine pigment uptake by enamel in all elapsed times post bleaching. The amount of wine pigment uptake by enamel treated with Whiteness HP Maxx was lower after 1 week than immediately after bleaching.

\section{DISCUSSION}

Scanning electron microscopic evaluations have been conducted on enamel surfaces treated with $35 \%$ hydrogen peroxide and evidences of surface morphologic alterations have been reported ${ }^{8,10,13,22}$. When a hydrogen peroxidecontaining bleaching agent was associated with preoperative etching and heat application, extensive structural changes in enamel were observed ${ }^{12,21}$.

Not only surface morphological alterations, but all changes promoted by bleaching agents were probably responsible for increased enamel wine staining susceptibility. Unbleached surfaces were more stain-resistant to wine than those bleached with $35 \%$ hydrogen peroxide in all elapsed times following bleaching, although it was possible to quantify pigment uptake by unbleached enamel. The wine pigments detected on bleached surfaces that were immersed in red wine immediately and 24 after $h$ bleaching were three or four times more concentrated than unbleached specimens (Figure 1).

An absorbance spectrophotometer was used to quantify the dye uptake by enamel surfaces submitted or not to bleaching ${ }^{5}$. Enamel staining susceptibility cannot be related to surface roughness alone, but also to enamel composition, water absorption rate due to permeability alterations, and irregularities left on bleached enamel surfaces, which could facilitate the accumulation of wine pigments and dyes ${ }^{1,3,8,20,21}$. In this study, flat and polished surfaces from subsurface enamel layer were evaluated, which can favor the effects of bleaching agents. The removal of the superficial, aprismatic layer by wet-grinding with $\mathrm{SiC}$ paper has been reported to improve the etching effects of some self-etching adhesive systems ${ }^{9,14,19}$ and to reduce fracture toughness and tensile strength after bleaching tratment ${ }^{6,16,17}$. Since the morphological structure and composition of the intact peripheral surface of the enamel is different from that of the middle enamel layer ${ }^{15}$, these differences can be favorable for bleaching effects in subsurface enamel surface, increasing wine staining.

The presence of wine pigments even in unbleached enamel could also result from the use of subsurface enamel instead of intact and ungrounded surfaces. Previous pilot studies were performed using intact surfaces and preliminary results showed that wine was retained in the irregularities of ungrounded enamel instead of the enamel uptake observed in this study. Thus, it was impossible to evaluate the effects of bleaching agents; since the external, aprismatic layer is more resistant to stain than subsurface enamel. Moreover, for both treated and unbleached enamel surfaces, the staining was only superficial and not uniform throughout the surface.

Although no significant differences were observed between bleached surfaces in the wine-immersion times of $24 \mathrm{~h}$ and 1 week post-bleaching, Whiteness HP Maxx induced more wine pigment uptake immediately after bleaching than Pola Office. However, for Whiteness HP Maxx, there was reduction on the amount of wine pigments detected in enamel after 1 week, while for Pola Office, the mean values of $\mathrm{mg}$ wine pigments $/ \mathrm{mL}$ remained the same for the three times elapsed after the bleaching. The individual effects of each bleaching agent on enamel structure were responsible for these different behaviors of enamel post-bleaching.

\section{CONCLUSIONS}

The results suggested that $35 \%$ hydrogen peroxide promoted alterations on enamel surface, which increased wine staining susceptibility up to 1 week following the bleaching, when compared to unbleached enamel surfaces. The tested null hypothesis was rejected since both whitening treatments influenced enamel susceptibility to staining.

\section{ACKNOWLEDGMENTS}

The authors are grateful to the Department of Pharmacology of the Dental School of Piracicaba/ UNICAMP. This study was supported by CNPq (\# 301769/ 2004-4), Brazil. 


\section{REFERENCES}

1- Arends J, Jongebloed WL, Goldberg M, Schuthof J. Interaction of urea and human enamel. Caries Res. 1984;18(1):17-24.

2- Arens D. The role of bleaching in esthetics. Dent Clin North Am. $1989 ; 33(2): 319-36$

3- Arwill T, Myrberg N, Söremark R. Penetration of radioactive isotopes through enamel and dentine. II. Transfer of $22 \mathrm{Na}$ in fresh and chemically treated dental tissues. Odontol Revy. 1969;20(1):4754

4- Attin T, Manolakis A, Buchalla W, Hannig C. Influence of tea on intrinsic colour of previously bleached enamel. J Oral Rehabil. 2003;30(5):488-94.

5- Cavalli V, Arrais CA, Giannini M, Ambrosano GM. Highconcentrated carbamide peroxide bleaching agents effects on enamel surface. J Oral Rehabil. 2004;31(2):155-9.

6- Cavalli V, Carvalho RM, Giannini M. Effect of carbamide peroxide bleaching agents on tensile strength of human enamel. Dent Mat. 2004;20(8):733-9.

7- Cavalli V, Giannini M, Carvalho RM. Effect of carbamide peroxide bleaching agents on tensile strength of human enamel. Dent Mater. 2004;20(8):733-9.

8- Hegedüs C, Bistey T, Flóra-Nagy E, Keszthelyi G, Jenei A. An atomic force microscopy study on the effect of bleaching agents on enamel surface. J Dent. 1999;27(7):509-15.

9- Kanemura N, Sano H, Tagami J. Tensile bond strength to and SEM evaluation of ground and intact enamel surfaces. J Dent. $1999 ; 27(7): 523-30$

10 - Ledoux WR, Malloy RB, Hurst RVV, Mcinnes-Ledoux P, Weinberg, R. Structural effects of bleaching on tetracycline-stained vital rat teeth. J Prosthet Dent. 1985;54(1):55-9.

11 - Lewinstein I, Hirschfeld Z, Stabholz A, Rotstein I. Effect of hydrogen peroxide and sodium perborate on the microhardness of human enamel and dentin. J Endod. 1994;20(2):61-3.

12- McGuckin RS, Babin JF, Meyer BJ. Alterations in human enamel surface morphology following vital bleaching. J Prosthet Dent. 1992;68(5):754-60

13 - Pinto CF, Oliveira R, Cavalli V, Giannini M. Peroxide bleaching agents effects on enamel surface microhardness, roughness and morphology. Braz Oral Res. 2004;18(4):306-11.

14- Perdigão J, Geraldeli S. Bonding characteristics of self-etching adhesives to intact versus prepared enamel. J Esthet Restor Dent. 2003;15(1):32-41.

15- Poole DFG, Johnson NW. The effect of different demineralizing agent on enamel surface studies by scanning electron microscopy. Arch Oral Biol. 1967;12:1621-34.

16- Seghi RR, Denry I. Effects of external bleaching on indentation and abrasion characteristics of human enamel in vitro. J Dent Res. $1992 ; 71(6): 1340-4$

17- Silva AP, de Oliveira R, Cavalli V, Arrais CA, Giannini M, de Carvalho RM. Effect of peroxide-based bleaching agents on enamel ultimate tensile strength. Oper Dent. 2005;30(3):318-24

18 - Shinkai RS, Cury AADB, Cury JA. In vitro evaluation of secondary caries development in enamel and root dentin around luted metallic restoration. Oper Dent. 2002;26(1):52-9.
19- Shinohara MS, Oliveira MT, Di Hipólito V, Giannini M, De Goes M. SEM analysis of the acid-etched enamel patterns promoted by acidic monomers and phosphoric acids. J Appl Oral Sci. 2006;14(6):427-35

20 - Rotstein I, Dankner E, Goldman A, Heling I, Stabholz A, Zalkind M. Histochemical analysis of dental hard tissues following bleaching. J Endod. 1996;22(1):23-5

21 - Titley K, Torneck CD, Smith D. The effect of concentrated hydrogen peroxide solutions on the surface morphology of human tooth enamel. J Endod. 1988;14(2):69-74.

22- Zalkind M, Arwas JR, Goldman A, Rotstein I. Surface morphology changes in human enamel, dentin and cementum, following bleaching: A scanning electron microscopy study. Endod Dent Traumatol. $1996 ; 12(2): 82-8$. 